\title{
The influence of removing the environmental stamp on air quality in Brasov
}

\author{
Costel Bucataru ${ }^{1}$ and Dan Savescu ${ }^{2}$ \\ ${ }^{1}$ Product Design, Mechatronics and Environment Department, Transilvania University of \\ Braşov, Romania \\ ${ }^{2}$ Product Design, Mechatronics and Environment Department, Transilvania University of \\ Braşov, Romania
}

E-mail: costel.bucataru@unitbv.com

\begin{abstract}
Air pollution means the presence in the air or in the atmosphere of foreign compounds of their normal composition, which at a certain concentration and depending on the time of action it generates disturbances in the natural balance, affecting human health and comfort or the flora's living environment and wildlife. The influence of some laws can change the air quality in a positive or negative way. The cancellation of the environmental stamp allowed the registration of hundreds of thousands of very old and very polluting cars in Romania. The consequence of such a decision was analysed in Brasov, which is a tourist city in central part of Romania.
\end{abstract}

Keywords: environment, urbanization, transport, pollution.

\section{Introduction}

A clean environment represents a healthy life, the state of the environment depends on each individual being and directly influences its life and health. Because it is a consequence of human activity, pollution has increased at the same time with the increasing number of people, the increase of their needs and the development of new technologies, as well as the urbanization at an increasingly alert rate.

Urbanization is the main factor generating pollution, being associated with the process of industrialization, modernization and development.

The air pollution carried by transport has two major features; the elimination of pollutants is very close to the ground, thus being high concentrations at very low heights. Another particularity refers to the concentration of emissions on the covered surface, which depends on the intensity of traffic and the possibility of ventilation of the street.

\section{The policies of the European Union}

The EU's long-term goal is to achieve levels of air quality that do not affect or induce unacceptable risks to human health and the environment. The EU acts on several levels to reduce exposure to air pollution: through legislation, through cooperation with sectors responsible for air pollution, as well as with international, national and regional authorities, non-governmental organizations and research. EU policies aim to reduce exposure to air pollution by reducing emissions and by setting air quality limits 
and targets. At the end of 2013, the European Commission adopted the Air Quality Package, which includes new measures to reduce air pollution.

\section{Pollution and its main source}

Air pollution harms human health and the environment. In Europe, the emissions of many atmospheric pollutants have decreased substantially over the last few decades, leading to an improvement in air quality in the region. However, atmospheric pollutant concentrations continue to be very high, and air quality problems persist. A significant proportion of Europe's population lives in areas, particularly cities, where exceedances of air quality standards occur: ozone pollution, nitrogen dioxide and particulate matter (PM) pose serious health risks. Several countries exceeded one or more emission limits in four major air pollutants in 2010. Therefore, reducing air pollution remains important.

Air pollution is a local, pan-European and hemispheric problem. Atmospheric pollutants emitted in one country can be transported into the atmosphere, contributing or leading to poor air quality in other areas.

Suspended powders, nitrogen dioxide and ground-level ozone are currently recognized as the three pollutants that most seriously affect human health. Long-term and maximum exposures to these pollutants vary in severity and impact, from minor effects on the respiratory system to premature death. About $90 \%$ of the inhabitants of cities in Europe are exposed to pollutants in concentrations above the air quality levels considered harmful to health. For example, fine airborne powders (PM2.5) in the air reduce life expectancy in the EU by over eight months. Benzopyrene is an increasingly worrying carcinogen that, in several urban areas, especially in central and Eastern Europe, is present in concentrations that exceed the threshold set for the protection of human health.

"Air pollution is harmful to human health and ecosystems. A large part of the population does not live in a healthy environment, according to current standards. In order to follow a sustainable path, Europe will have to show ambition and not to abide by the current legislation".

Hans Bruynincks, World Environment Agency, WEA, Director

Air pollution also affects the environment. For example:

- Acidification was substantially reduced between 1990 and 2010 in areas of Europe with sensitive ecosystems, under the influence of acid deposition of excess nitrogen and sulfur compounds.

- Eutrophication is an environmental problem caused by the excess of nutrients entering the ecosystems. Less progress has been made in this area. The surface of sensitive ecosystems affected by the excess of atmospheric nitrogen decreased very little between 1990 and 2010 .

- High ozone concentrations lead to crop destruction. Most agricultural crops are exposed to ozone levels that go beyond the EU's long-term goal of protecting vegetation. This problem concerns a considerable proportion of agricultural areas, especially in southern, central and eastern Europe.

The air quality in Europe has not always improved with the general reduction of the anthropogenic emissions (human products) of atmospheric pollutants. The causes are complex:

- There is not always a clear linear link between the emission drop and the air pollutant concentrations observed in the air;

- There is an increasing contribution of long-distance transport of atmospheric pollutants from other countries in the northern hemisphere to Europe.

Therefore, targeted efforts are still needed to reduce emissions in order to further protect human health and the environment in Europe.

Air pollution sources are varied and can be anthropogenic or natural:

- Combustion of fossil fuels in electricity generation, transport, industry and households;

- Industrial processes and use of solvents, for example in the chemical and extractive industries;

- Agriculture;

- Waste treatment;

- Volcanic eruptions, airborne dust, sea salt dispersion, and emissions of volatile organic compounds from plants are examples of natural emission sources. 
The highest weight for mobile sources of pollution is represented by the substances released from the exhaust gases. The quantity, type and concentration of the pollutants emitted depend on the type of vehicle, the nature of the fuel used but also its technical state.

Road traffic contributes to the dust pollution caused by the tires of cars, both by stopping them and by incomplete combustion.

Material particles are a category of air pollutants that greatly affect human health. They include in their composition: nitrates, sulfates, carbon, dust and salt. These material particles are suspended particles with aerodynamic diameter of 10 microns (PM 10) or 2.5 microns (PM 2.5).

Integrated monitoring represents "a complete system for acquiring environmental quality data obtained on the basis of long-term systematic measurements on a set of parameters and indicators, with spatial and temporal coverage that can ensure the possibility of pollution control" [1]

According to the provisions of Law no. 104/2011 regarding the quality of the ambient air, the responsibility for monitoring the quality of the ambient air in Romania lies with the competent authorities for environmental protection.

Table 1. Law 104 for limits of values of suspended particles

LAW no. 104 of June 15,2011

Suspended particles - PM10

Limit values $50 \mu \mathrm{g} / \mathrm{m}^{3}$ - the daily limit value for the protection of human health

$40 \mu \mathrm{g} / \mathrm{m}^{3}$ - the daily limit value for the protection of human health

LAW no. 104 of June 15,2011

Suspended particles - PM10

Target value $25 \mu \mathrm{g} / \mathrm{m}^{3}$ - annual target value

$20 \mathrm{ug} / \mathrm{m}^{3}$ - the annual limit value to be reached by January 1,2020

Monitored pollutants, measurement methods and techniques, limit values, alert thresholds, information and criteria for the location of monitoring points are from European regulations.

\section{Pollution in Brasov and the influence of road traffic}

Brașov County is located in the central - eastern part of Romania, on the middle course of the Olt within the Carpathian arc being bounded on the east by the Ciucașului Mountains, on the south by the Piatra Mare, Bucegi, Piatra Craiului mountains and the Făgăras massif and in the north-east by the Baraolt mountains and the depression between Olt and Târnave respectively. The surface of the county is $5363.1 \mathrm{~km} 2$, respectively $2.2 \%$ of the country's surface and is intersected by the parallel $46^{\circ}$ north latitude passing through the Jibert and Ormenis localities.

The Agency for Environmental Protection Brasov (APM BV) is organized and operates in accordance with the provisions of Government Decision no. 459/2005 regarding the reorganization and functioning of the National Agency for Environmental Protection, of the GEO no. 195 / 22.12.2005 regarding the protection of the environment, approved by Law 265/2006 as well as of other applicable normative acts. It is a public institution with legal personality, with a decentralized public service status, financed from the state budget.

In the automatic network the measurements were made at the 5 automatic stations by monitoring of the air quality from the Brasov agglomeration, located, according to the criteria indicated in the legislation, in areas representative of each type of station [2]:

- Traffic station: station BV1 - Calea Bucureşti Boulevard - located in traffic area intensive;

- Urban background station: station BV2 - str. Castanilor - located in the area residential, to highlight the degree of exposure of the population to the level of pollution urban;

- Traffic station: station BV3 - B-dul Gării - located in an area with heavy traffic and heavy traffic;

- Suburban station: station BV4 - Sânpetru commune - having as objective assessment of ozone exposure of population and vegetation from the edge of agglomeration; 
Thoth Publishing House

- Industrial background station: station BV5 - B-dul Al. Vlahuță - whose location resulted from the preliminary assessment of the air quality in order to highlight the influence of the emissions from the industrial area on the pollution level in the southern area of Brasov municipality.

The evolution of the average annual concentrations regarding the pollution with material particles, in Braşov county from 2014 to 2017, was increasing until 2017, the highest values being obtained at the monitoring station BV 3, an area with an intensity of very high road traffic (Figure 1)

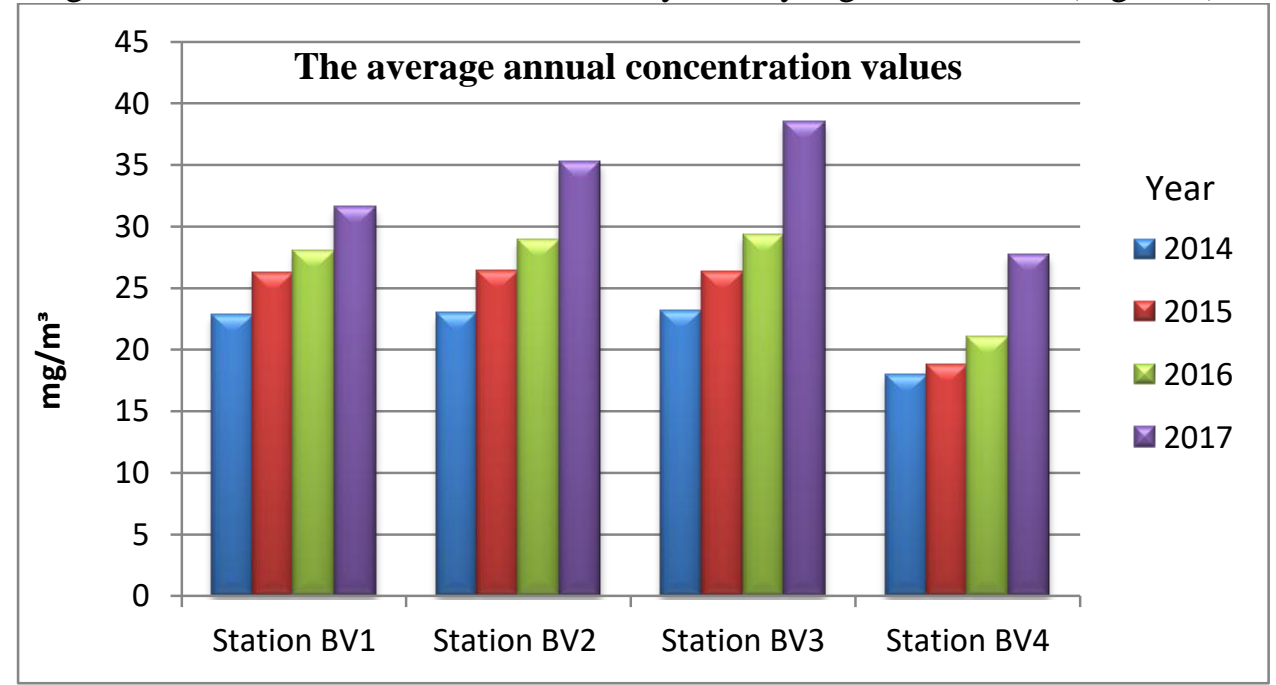

Figure 1. The average annual concentration values

It is observed that the level of pollution is increasing from year to year, regardless of the station for the monitoring of air pollutants and its location. Although all values are within the limits of the law, they tend to increase.

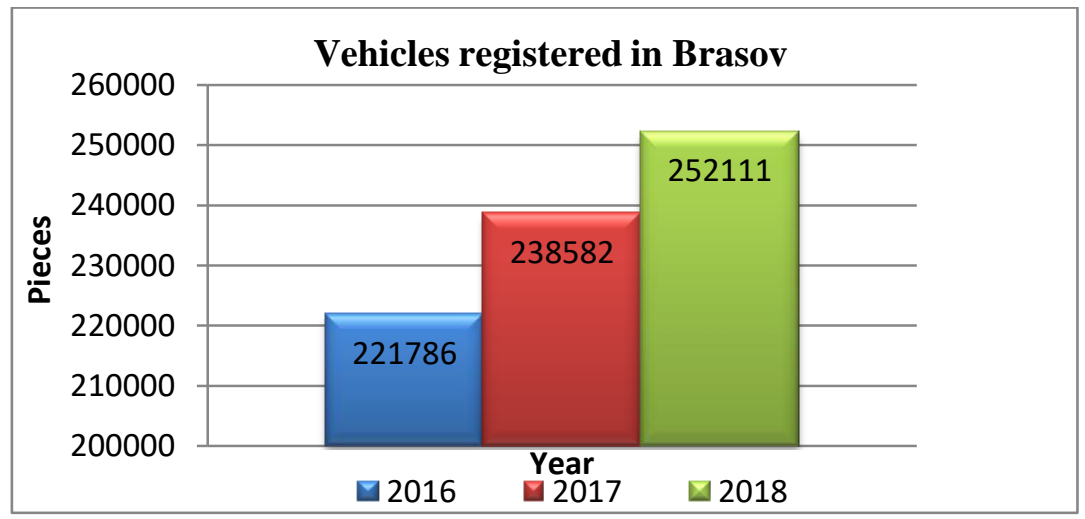

Figure 2. Vehicles registered in Brasov

This increase continues, especially in 2017 related to the cancellation of the environmental stamp. Until the abolition of this law, in the case of very old cars, the drivers had to pay a stamp duty higher than the value of the vehicle itself. That is why many were hesitant to buy such cars. In time after eliminating the tax, we risk to have on the streets many cars older than 10-15 years, which pollute a lot.

And in order to correlate the increase of the pollution level with the number of old cars, in Figure 2 it is observed that only in the Brasov labor force were registered over 30 thousand cars in less than two years since the stamp cancellation.

The consequences of the cancellation of the environmental stamp for old cars that pollute a lot are very serious in the long term, from one year to another increasing the pollution level by at least $5 \mathrm{mg}$ per cubic meter. Such a decision negatively affected the air quality. 
Thoth Publishing House

In the long term, we must be aware of future generations and develop sustainable and friendly with the environment. The current state of air quality was interpreted according to the monthly data of the reports displayed on the website of the Environmental Protection Agency of Brasov.

\section{Some measures that can clear the air in the cities of Romania in a very short time}

According to the specialists in the field of air quality, there are concrete measures that can be taken by both administrations and each one of us to limit air pollution. Let's start with ourselves, because that will work even today.

Individual behaviour of each of us has a major and immediate impact on the air quality. Here are some of the solutions we can personally call before pointing fingers at the authorities.

- Use of public transport instead of personal car, at least a few days a month.

- Sharing a car with work colleagues for the shuttle

- Use of the machine only if it is in very good technical condition (active EGR circuit, properly inflated tires, eco-friendly brake pads, etc.)

- Composting plant remains instead of burning them (which is illegal anyway)

- Reduce the number of trips by car if they are not essential (you can also walk to shopping, etc.) In addition to these individual measures, the intervention of the authorities is certainly needed. There are a number of measures with a massive impact on air quality, which can be taken quickly:

- High-water washing of streets and sidewalks and / or subsequent suction (reduces suspended particles by about $70 \%$ at the sidewalk level)

- Planting live fences and perennial bushes on the edge of boulevards and streets (reducing pollutants by $15-60 \%$ on the sidewalk, depending on the pollutant - nooks, PM2.5, PM10, etc.)

- Prohibiting the use of leaf blowers and lawnmowers and their replacement with electric blowers

- Prohibition, monitoring and punishment of the burning of vegetal debris both in the city and in the surrounding villages

- Massive interventions in traffic to punish non-compliant cars (EGR removed etc. obviously requires collaboration with RAR)

- Creation of a system of dozens of real-time air quality measurement sensors, disposed in both busy and residential traffic areas. In a first phase, one can collaborate with the existing networks, after they have been calibrated. Subsequently, Romania should have its own network with thousands of sensors, especially in big cities.

More complex measures that can be taken by the authorities within 6 months - maximum two years:

- Careful monitoring of garbage pits, cement plants, incinerators and any kind of waste, as well as close monitoring of city factories and all sources of gas combustion (including residential blocks). If it is chosen to build incinerators to replace the current landfills, they should use state-of-the-art technology and not have to bring in trash from other areas.

- Careful monitoring of the construction sites and of the interventions in the infrastructure, because the dust resulting from this remains in the atmosphere and is full of very toxic substances.

- Arrangement of green spaces, planting of trees and green bushes all year round, especially shade resistant. They have the ability to retain and filter dust much larger than the ordinary lawn. In addition, they help biodiversity.

- Reducing concrete spaces dedicated to surface parking and expensive parking to stimulate the construction of underground parking replaced by surface parks. The one million cars in Bucharest parked on the ground are just as many sources of pollution, regardless of their technical condition.

- Creation of bicycle tracks and electric scooters that cross the city on its axes, on the central and middle ring. These would reduce car trips over distances shorter than 5 kilometers.

- Massive investment in electrified public transport and phasing out of diesel buses. All new buses should be electric so that in no more than ten years will there be no diesel bus in the city's car park. 
Complex measures with medium and long term strategy (6 months - 5 - 10 years)

- Making green roofs on schools and other buildings, especially in areas with a high density of housing. There are 7 million square meters of terraces in Bucharest, which currently reach over $70 \mathrm{C}$ during the summer. The use of a combination of green roof (sedum-like plants) and semitransparent solar panels would increase the city's green area by over $30 \%$, with an immediate effect on the "heat island" phenomenon above the city, which raises the temperature and exacerbates pollution.

- Planting forests around the city and creating green axes that cross the city. These axes can be 50$100 \mathrm{~m}$ wide and can include bicycle lanes and pedestrian areas surrounded by greenery, thus becoming a much healthier alternative than boulevards full of car traffic.

- Installation of air purifiers in nurseries, kindergartens, schools, hospitals, public spaces. This measure should be only temporary and taken only in those areas where the reduction of air pollution cannot be done within a reasonable time.

- Investing in underground public transport and in the light surface metro as the main means of transport in the city. The subway is the most efficient public transport solution both in terms of pollution and energy consumption.

- Reconfigure transit traffic to bypass the city (park \& ride, belt, commuter trains, etc.). This is where a strategy of the Ministry of Transport is needed, because the mayors do not have the financial capacity to execute such projects on their own.

\section{Conclusions}

Particle size is directly related to the potential to cause effects. An important problem is the particles with an aerodynamic diameter of less than 10 micrometers, which pass through the nose and throat and enter the pulmonary alveoli causing inflammation and intoxication. People with cardiovascular and respiratory diseases, children, the elderly and asthmatics are particularly affected.

Children under the age of 15 inhale more air, and consequently more pollutants. They breathe faster than adults and tend to breathe more into the mouth, practically bypassing the natural filter in the nose. They are especially vulnerable because their lungs are not developed and lung tissue that develops in childhood is more sensitive.

Powder pollution worsens the symptoms of asthma, cough, chest pain and respiratory distress. Long-term exposure to a low concentration of powders can cause cancer and premature death.

The vegetation, following the action of the powders, often presents burns, phenomena of dwarfism, frequent chlorotic specimens. Due to the filling of the stomata through the crust that is formed, the gas exchange is no longer necessary, the process of photosynthesis, or rather the process of transformation of assimilated substances into plant matter is much diminished.

\section{References}

[1] Rojanschi, Vl. Bran, F, Diaconu Gh (1997), Environmental protection and engineering, Economic Publishing House, Bucharest

[2] *** A.P.M. Brasov (2018) Report on the state of the environment in the county of Brasov for the year 2018 